\title{
Crystalline Microstructure and Dielectric Properties of Oriented Poly(Ethylene-co-Tetrafluoroethylene)
}

\author{
Yun Huang ${ }^{1,2}$, Daniel F. Miranda ${ }^{1}$, Ciprian Iacob ${ }^{1}$, Shihai Zhang ${ }^{3}$, James Runt ${ }^{1 *}$ \\ ${ }^{1}$ Department of Materials Science and Engineering, The Pennsylvania State University, \\ University Park, Pennsylvania, 16802 \\ ${ }^{2}$ State Key Laboratory of Polymer Materials Engineering of China, Polymer Research \\ Institute of Sichuan University, Chengdu 610065, China \\ ${ }^{3}$ PolyK Technologies, LLC, 2124 Old Gatesburg Road, State College, PA 16803 \\ *Corresponding author. Email address: runt@ matse.psu.edu
}

Keywords: crystalline polymer microstructure, dielectric breakdown, polymer dynamics

\begin{abstract}
In the present investigation, we explore the influence of uniaxial orientation and subsequent thermal annealing on semi-crystalline poly(ethylene-tetrafluoroethylene) (ETFE) microstructure and dynamics, and the connection to dielectric breakdown strength. Understanding the influence of crystalline microstructure on dynamics and breakdown, and in turn how processing influences microstructure, is critical for establishing rational design of polymer dielectrics. When drawn below the glass transition temperature $\left(T_{g}\right)$, the Weibull breakdown strength decreases compared to that of the undrawn precursor film, but increases on thermal annealing near or above $\mathrm{T}_{\mathrm{g}}$. This behavior is associated with the formation and elimination of drawing-induced microvoids, respectively. When drawn above $\mathrm{T}_{\mathrm{g}}$, the breakdown strength increases to $\sim 870 \mathrm{MV} / \mathrm{cm}$, dominated by orientation of amorphous segments, and decreases on thermal annealing above $\mathrm{T}_{\mathrm{g}}$ to near that of the undrawn film.
\end{abstract}




\section{Introduction}

Advanced polymer film capacitors are desired for continued miniaturization and increased functionality of modern electronic devices, including for use in pulsed power and power conditioning applications. Biaxially-oriented, semi-crystalline polypropylene (BOPP) is the predominate polymer film capacitor in use today: BOPP exhibits very low dielectric loss $(\sim 0.02 \% \tan \delta)$ and high dielectric breakdown strength, critical features for commercially relevant film capacitor materials. ${ }^{1}$ However, non-polar BOPP has a rather low dielectric constant (2.2 at $1 \mathrm{KHz},{ }^{2}$ originating almost entirely from electronic polarization), limiting the maximum achievable energy density. As a consequence, considerable research has been devoted to the rather difficult challenge of enhancing polymer film dielectric constant, while

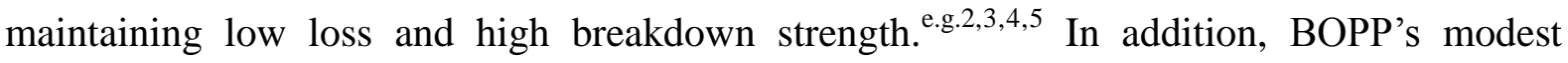
melting point $\left(\mathrm{T}_{\mathrm{m}}, \sim 160{ }^{\circ} \mathrm{C}\right)$ precludes it for use in higher temperature applications (in the absence of active capacitor cooling).

Of particular importance in capacitor films is the dielectric loss, which contributes to capacitor inefficiency as well as Joule heating, the latter important since practical dielectric breakdown is likely thermo-mechanical in nature. ${ }^{6}$ Contributions to dielectric loss arise from dissipative energy from molecular motions and, at temperatures above the glass transition $\left(\mathrm{T}_{\mathrm{g}}\right)$, to conduction contributions from impurity ionic species (controlled by polymerization processes, purification and subsequent manufacturing). For a given material / resin grade, reduction in dielectric losses can be achieved by suppressing amorphous phase molecular motions, through maximizing the degree of crystallinity and otherwise constraining the amorphous segments. Mobility of non-crystalline segments is restricted by attachment to crystals or can be constrained by mechanical drawing.

Much research has been conducted on strain-induced crystallization of crystalline polymers and their oriented microstructure on drawing, and separately on dielectric properties of crystalline polymers including dielectric breakdown. However, there has been little work devoted to connecting the two, rather surprising considering most polymers considered for film capacitors are semi-crystalline. There have been a modest number of reports on the role of chemical structure, crystallinity, molecular motion, defects and other factors on the breakdown strength of dielectric polymers. ${ }^{7,8,9}$ For example, the dielectric breakdown 
strength of polyethylene has been reported to increase with crystallinity, ${ }^{8}$ and biaxial orientation of polypropylene also greatly increases the breakdown strength of the polymer film. ${ }^{1}$

Semi-crystalline fluoropolymers are a higher $\mathrm{T}_{\mathrm{m}}$ alternative to BOPP, in particular poly(ethylene-co-tetrafluoroethylene) [ETFE] and poly(tetrafluoroethylene) -co-(perfluoroalkylvinylether) [PFA]. Although their dielectric constants are in the same range as BOPP, they can be melt extruded into thin films, have high dielectric stability at elevated temperatures, and exhibit very low dielectric loss. ${ }^{10}$ Building on our previous work, ${ }^{11,12}$ we focus in this paper on the role of uniaxial orientation and subsequent thermal annealing on the semi-crystalline microstructure and low electric field dynamics of ETFE, as well as high field dielectric breakdown measurements on selected drawn and annealed ETFE films. Experimental Weibull dielectric breakdown strengths are found to increase with uniaxial orientation (draw ratio $=3$ ) to values as high as $870 \mathrm{MV} / \mathrm{cm}$, over $10 \%$ larger than commercial BOPP films measured under similar conditions. ${ }^{13,14}$ Understanding how crystalline microstructure affects polymer dynamics and breakdown strength, and in turn understanding how processing conditions affect microstructure, is critical for establishing rational design of polymer dielectrics utilizing ETFE and similar polymers.

\section{Experimental}

Materials. ETFE resin (Tefzel ${ }^{\circledR} 200$ ), a nearly alternating copolymer of ethylene and tetrafluoroethylene, was obtained from DuPont. Films were extruded using a 1 inch single screw extruder with a 6 inch flex lip film die, at a temperature of $300{ }^{\circ} \mathrm{C}$. It was determined that extrusion imparted some preferred orientation to the film, which could complicate the findings of later experiments. Therefore, prior to any further experiments, the as-extruded film was pre-treated at $140{ }^{\circ} \mathrm{C}$ for $3 \mathrm{hrs}$. This treatment was shown to effectively erase the history imparted by extrusion. ${ }^{11}$ Samples for drawing were then cut from the unoriented film and marked with horizontal and vertical gage lines using a square grid template, each line separated by $0.5 \mathrm{~cm}$.

Thinner ETFE film $(\sim 12 \mu \mathrm{m})$ was used for dielectric breakdown measurements and provided by PolyK Technologies, produced with a single screw extruder at $310^{\circ} \mathrm{C}$. As above, 
these films were initially pre-treated at $140{ }^{\circ} \mathrm{C}$ for $3 \mathrm{hrs}$, and drawn and annealed following the same procedure described below for the thicker film. Wide-angle X-ray diffraction (WAXD), differential scanning calorimetry (DSC) and dynamic mechanical analysis (DMA) results on the thinner films confirmed that both microstructure and relaxations of the thinner films underwent very similar changes during the drawing and annealing processes compared to the somewhat thicker films.

Unoriented films were uniaxially drawn at $50{ }^{\circ} \mathrm{C}$ and $140{ }^{\circ} \mathrm{C}$ (i.e., below and above the reported $\mathrm{T}_{\mathrm{g}} \sim 100{ }^{\circ} \mathrm{C}^{15,16}$ ), using an Instron Model 5866 equipped with an air oven and pneumatic grips. For films drawn at $140{ }^{\circ} \mathrm{C}$, after drawing to a predetermined extension ratio $(\lambda)$, they were maintained at the particular $\lambda$ and cooled for 6 minutes (during that time the temperature decreased to $60-70{ }^{\circ} \mathrm{C}$, i.e., below $\mathrm{T}_{\mathrm{g}}$ ). The tension was subsequently released and the film was removed from the temperature chamber. This step was used to avoid sample shrinkage after removal from the clamps. Films drawn at $50{ }^{\circ} \mathrm{C}$ were taken out of the temperature chamber immediately after the conclusion of drawing. Finally, the drawn films were annealed at $110{ }^{\circ} \mathrm{C}$ and $140{ }^{\circ} \mathrm{C}$ (in the vicinity of, and above $\mathrm{T}_{\mathrm{g}}$ ) for different times. Samples in this study were coded based on preparation conditions. For example, $50 \mathrm{C}-4 \lambda-140 \mathrm{C}-2 \mathrm{~min}$ represents that the film was drawn at $50{ }^{\circ} \mathrm{C}$ to an draw ratio of $4 \lambda$ and annealed at $140{ }^{\circ} \mathrm{C}$ for 2 minutes. Other samples were likewise coded.

Characterization. DSC was conducted using a TA Instruments model Q2000 and used to determine the degree of crystallinity under different preparation conditions. Circular samples were obtained for each sample using a hole puncher, with each sample weighing between 3 and $5 \mathrm{mg}$. The samples were packed into standard aluminum DSC pans, and heated from $40{ }^{\circ} \mathrm{C}$ to $300{ }^{\circ} \mathrm{C}$ at a rate of $5{ }^{\circ} \mathrm{C} / \mathrm{min}$. Measurements on all samples were conducted 3 times. Crystallinities were determined by comparison of measured heats of fusion to that of the $100 \%$ crystalline polymer $\left(113 \mathrm{~J} / \mathrm{g}^{17}\right)$.

Small-angle X-ray scattering (SAXS) and WAXD were used to characterize the morphology of the films. SAXS data were collected using a Molecular Metrology instrument with a $\mathrm{Cu} K \alpha$ radiation source $(\lambda=0.154 \mathrm{~nm})$ at $45 \mathrm{kV}$ and $66 \mathrm{~mA}$, using a two-dimensional multiwire detector with a sample-to-detector distance of $1.5 \mathrm{~m}$. The wavevector range (q) was calibrated by a standard sample of silver behenate and the scattered intensity converted to an 
absolute differential cross-section ( $\mathrm{cm}^{-1}$ units) by a high density polyethylene secondary standard. ${ }^{18}$ WAXD data were collected on a Rigaku DMAX/rapid micro diffractometer in transmission mode, using a copper point-focused source $(\lambda=0.154 \mathrm{~nm})$ at $50 \mathrm{kV}$ and $40 \mathrm{~mA}$.

DMA measurements were carried out on a TA Instruments model DMA Q800, equipped with a NPC cooler using liquid nitrogen. Samples were prepared as rectangular strips and mounted in standard tension clamps provided by TA Instruments. The film draw direction is oriented parallel to the DMA stress direction. A temperature sweep was carried out from $-150{ }^{\circ} \mathrm{C}$ to $200{ }^{\circ} \mathrm{C}$, with a heating rate of $3{ }^{\circ} \mathrm{C} / \mathrm{min}$, at a constant strain of $0.25 \%$ and frequency of $1 \mathrm{~Hz}$. Data were collected on heating.

Low electric field dielectric relaxation spectroscopy measurements were performed using a Novocontrol GmbH Concept 40 broadband dielectric spectrometer. Frequency sweeps were performed isothermally from $0.1 \mathrm{~Hz}$ to $10 \mathrm{MHz}$ in the temperature range from $-150{ }^{\circ} \mathrm{C}$ to $200{ }^{\circ} \mathrm{C}$, with data collected on heating. The analyzer was supported by a Quatro temperature controller providing temperature stability better than $0.1{ }^{\circ} \mathrm{C}$. Two brass electrodes were used to create a parallel plate capacitor geometry. The applied voltage for each experiment was $1.5 \mathrm{~V}$.

Dielectric breakdown measurements were carried out on metalized film specimens with $50 \mathrm{~nm}$ thick gold electrodes on both sides. The diameter of the metalized area was $3 \mathrm{~mm}$. Specimens were immersed in a silicone dielectric fluid and a DC voltage was applied at a ramp rate of $500 \mathrm{~V} / \mathrm{s}$. The film thickness for dielectric breakdown measurements was typically between 7 and $13 \mu \mathrm{m}$. A minimum of 30 measurements were made on each sample type, and all results were obtained at similar ambient temperature and humidity conditions. The dielectric breakdown strength was determined using conventional Weibull statistical analysis, where the Weibull cumulative distribution function is defined as:

$$
P=1-\exp \left[-\left(E / E_{b}\right)^{\beta}\right]
$$

$\mathrm{E}$ is the measured electrical breakdown strengths of individual test areas and $\beta$ is the shape parameter of the probability distribution, inversely correlated with the width of the distribution. $\mathrm{E}_{\mathrm{b}}$ is the Weibull dielectric breakdown strength, that is, $63 \%$ of the specimens 
statistically fail at an electric field below $\mathrm{E}_{\mathrm{b}} \cdot{ }^{19,20,21}$

\section{Results and Discussion}

\section{Melting Behavior}

Prominent melting endotherms were observed for all samples, as shown in Figure 1 for drawn films annealed at $140{ }^{\circ} \mathrm{C}$. DSC traces for drawn films annealed at $110{ }^{\circ} \mathrm{C}$ are displayed in Figure S1 and all melting points and degrees of crystallinity are tabulated in Table S1. The observed $\mathrm{T}_{\mathrm{m}} \mathrm{s}$ are independent of both draw temperature and annealing conditions, having a value of $\sim 266^{\circ} \mathrm{C}$. Crystallinities of oriented films ( 46\%) are somewhat higher than that of the unoriented precursor film (40\%), as would be expected from some strain-induced crystallization during drawing, although the influence of annealing on crystallinity is negligible. Clear $\mathrm{T}_{\mathrm{g}} \mathrm{s}$ in the expected temperature range (ca. $100{ }^{\circ} \mathrm{C}$, see the DMA and DRS sections that follow) are not observed in the DSC traces due to presence of crystallinity and transition broadening, as is common for semi-crystalline polymers. However, for the annealed samples a second small endotherm is observed and its temperature location

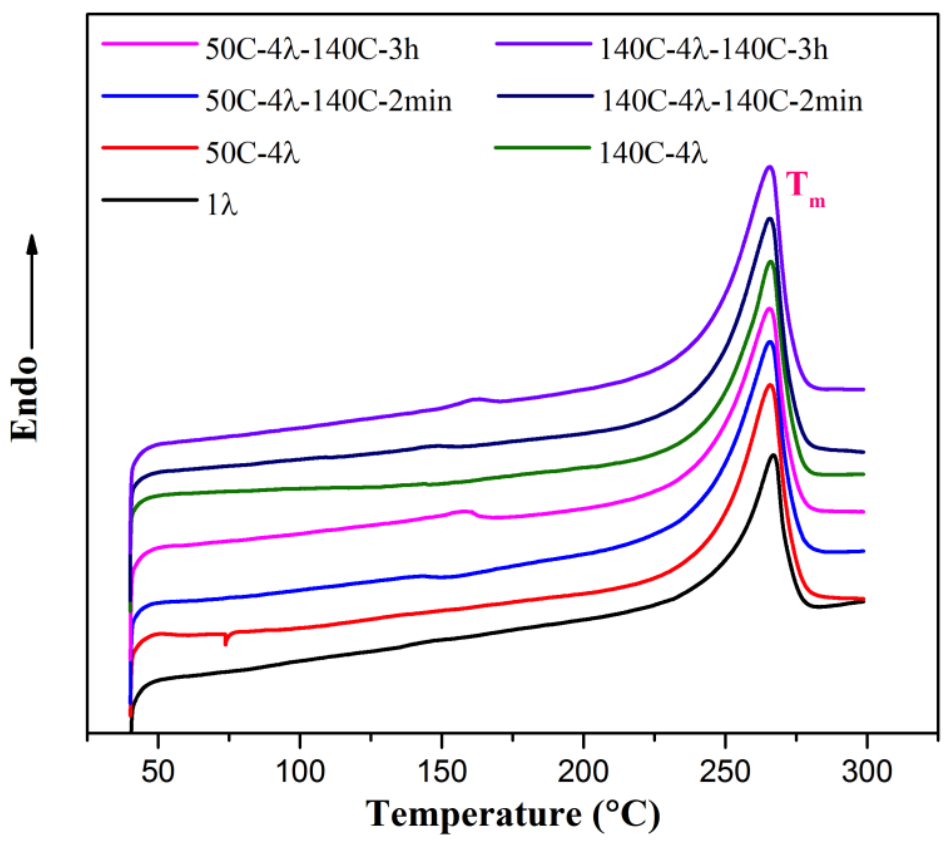

Figure 1. DSC thermograms of drawn films annealed at $140{ }^{\circ} \mathrm{C}$.

is a little higher than the annealing temperature (see Figure 1 and S1). The transition shifts to high temperatures and increases in magnitude with increasing annealing time. Similar behavior has been reported frequently for many semi-crystalline polymers, ${ }^{\text {e.g.22,23,24,25 }}$ and has 
been explained by either the melting of small crystals formed on annealing in amorphous regions between primary lamellae, ${ }^{22,23}$ enthalpy recovery of segments in an amorphous 'mesophase', or rigid amorphous fraction (RAF). ${ }^{24,25}$

\section{Crystalline Microstructure}

WAXD and SAXS measurements were conducted to evaluate changes in microstructure resulting from uniaxial orientation and subsequent annealing. Figure 2 displays representative 2D WAXD and SAXS patterns of the unoriented and oriented films (drawn and annealed at $\left.140{ }^{\circ} \mathrm{C}\right) .2 \mathrm{D}$ scattering patterns for the remaining oriented and annealed films are shown in Figure S2. For the unoriented precursor film, both WAXD and SAXS patterns displays ring-like, isotropic scattering, corresponding to an unoriented morphology. For uniaxially deformed films, the scattering patterns are indicative of an anisotropic lamellar morphology. Annealing the oriented films does not have any significant effect on the WAXD patterns, but increases the intensity of the SAXS scattering features.

(a)

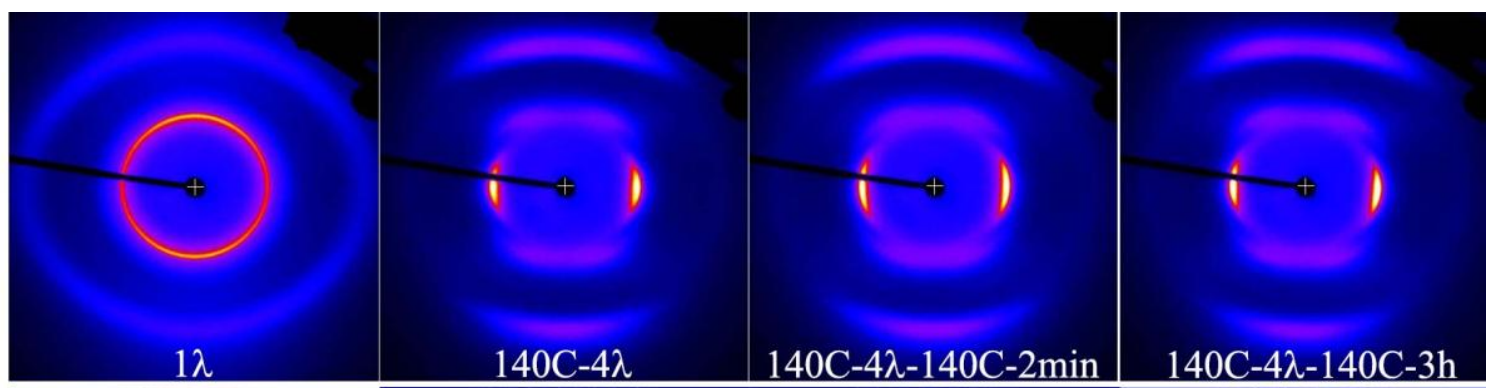

(b)

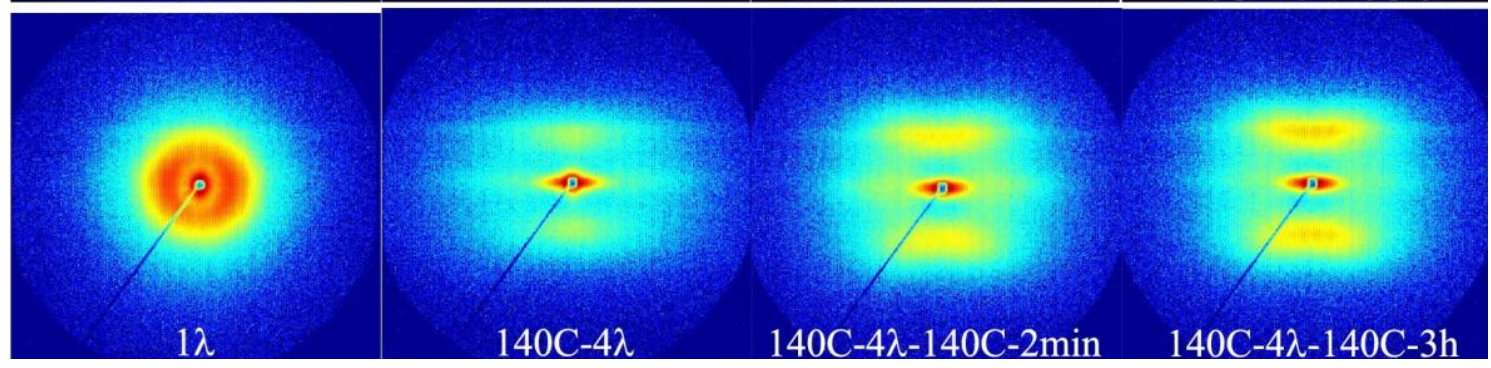

Figure 2. (a) WAXD and (b) SAXS 2D scattering patterns for films drawn at $140{ }^{\circ} \mathrm{C}$ and subsequently annealed at $140{ }^{\circ} \mathrm{C}$ for $2 \mathrm{~min}$ and $3 \mathrm{hr}$. The draw direction is along the vertical axis of the images. 
The WAXD patterns for all films display two primary diffraction rings or arcs at $\sim 19.5^{\circ}$ and $40^{\circ} 2 \theta$, corresponding to (120) and (002) planes of the orthorhombic unit cell, respectively. ${ }^{26}$ There is a contribution from (200) planes, ${ }^{26}$ best seen as a shoulder near $23^{\circ}$ in the azimuthally averaged 1D scattering profiles (Figures 3 and S3). As is typical for semi-crystalline ETFE, the amorphous halo is not clearly evident and is presumably hidden under the (120) diffraction peak. After drawing, the scattering intensity becomes concentrated into diffraction arcs arising from the oriented lamellar morphology. As noted previously ${ }^{11,26}$, a prominent feature in the $2 \mathrm{D}$ patterns of the drawn films is the strong equatorial arcing of the (002) planes, indicating the lamellar crystal c-axis (chain axis) is aligned along the drawing direction. As noted earlier, after annealing at either temperature, the 2D WAXD patterns are nearly identical to that of the parent oriented film, demonstrating that annealing at 110 or $140{ }^{\circ} \mathrm{C}$ has little effect on unit cell orientation.

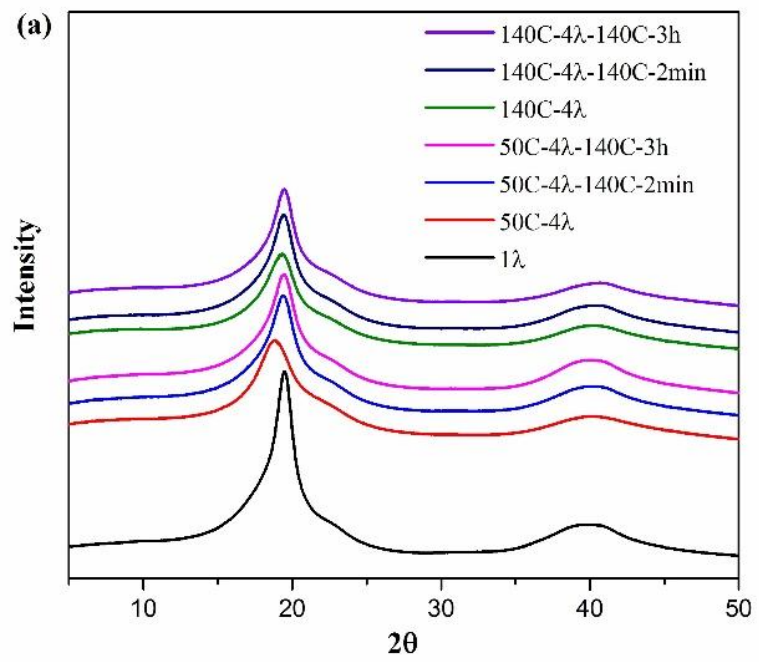

Figure 3. Azimuthally averaged 1D WAXD profiles of drawn films annealed at $140{ }^{\circ} \mathrm{C}$.

After drawing to $4 \lambda$ (50C-4 $\lambda$ and $140 \mathrm{C}-4 \lambda)$, the diffraction peak at $\sim 19.5^{\circ}$ becomes broader compared to the unoriented film: the full width at half maximum (FWHM) increases from $1.3^{\circ}$ for the unoriented film to $2.8^{\circ}$ and $2.5^{\circ}$ for $50 \mathrm{C}-4 \lambda$ and $140 \mathrm{C}-4 \lambda$, respectively. These results indicate that crystals with reduced lattice continuity ("crystallite size") are created in the drawing process. In addition, after drawing (particularly at $50{ }^{\circ} \mathrm{C}$ ), the peak at $\sim 19.5^{\circ}$ shifts to lower angles (d-spacing increases), suggesting slightly reduced packing of crystal chain segments (Table S2). When annealed at $140{ }^{\circ} \mathrm{C}$ for 2 minutes, the d-spacing and 
FWHM decrease quickly to the original values, and show little change with further annealing time. Similar behavior is observed for the oriented films annealed at $110{ }^{\circ} \mathrm{C}$, but the changes occur somewhat more gradually.

\section{Small-Angle X-ray Scattering}

Azimuthally averaged 1D SAXS profiles of all films are displayed in Figures 4 and S4. The 2D pattern of the unannealed film drawn below $T_{g}(50 C-4 \lambda$, see Figure $S 2$ panel $d)$ consists of an elliptical streak along the equator. Similar scattering has been observed on many occasions for uniaxially drawn crystalline polymers. ${ }^{27,28,29}$ The strong scattered intensity at low angles suggests that this feature represents scattering from microvoids, arising from high scattering contrast between the solid polymer and air. In addition, no scattering maximum is observed for $50 \mathrm{C}-4 \lambda$ suggesting little scattering contrast between lamella and interlamellar amorphous layers. This is in keeping with oriented amorphous segments forming what has been termed an oriented 'mesophase' with higher electron density (i.e., closer to that of the lamellae) $)^{30,31}$.
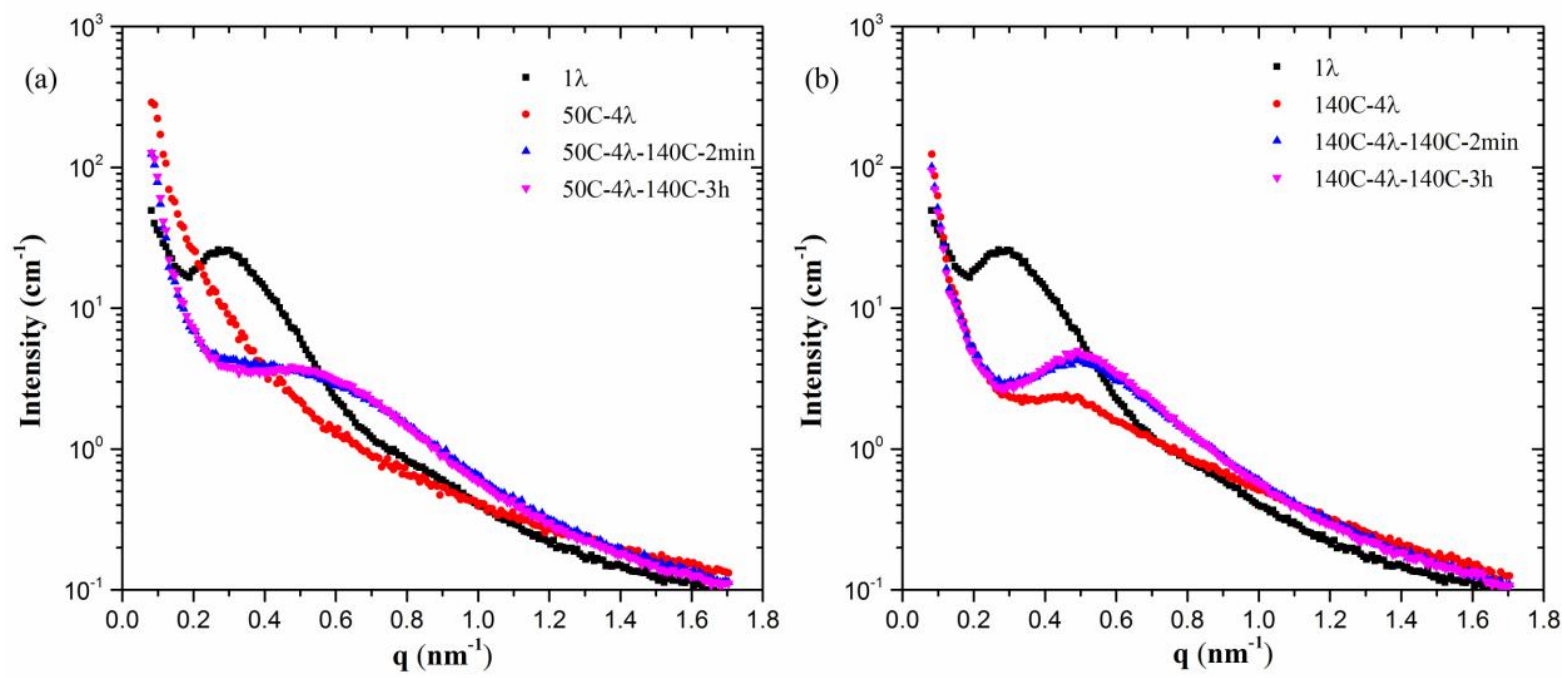

Figure 4. 1D azimuthally averaged SAXS profiles on an absolute intensity scale for films draw at $50{ }^{\circ} \mathrm{C}$ (a) and $140{ }^{\circ} \mathrm{C}$ (b), and subsequently annealed at $140{ }^{\circ} \mathrm{C}$.

Annealing films drawn at $50{ }^{\circ} \mathrm{C}$ at $140{ }^{\circ} \mathrm{C}$ (Figures 4a and S2 panel d) leads to a 
reduction in the extent of equatorial streaking, a bar-like pattern along the meridian, and a broad scattering peak in the 1D profile. The lamellae are well oriented with their chain axes along the draw direction, and the increase in scattering contrast between the lamellae and

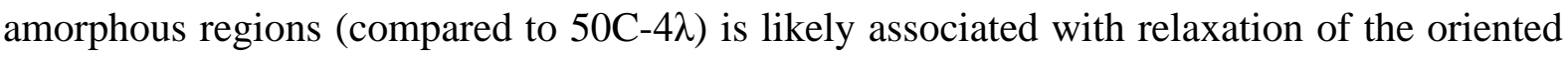
amorphous mesophase when annealed at $140{ }^{\circ} \mathrm{C}$. Mean long periods are roughly half of that of the unoriented sample (i.e., 21 vs $\sim 12 \mathrm{~nm}$, see Table S2). Similar behavior has been reported previously and proposed to arise from lamellar fragmentation/slip and some strain-induced crystallization during deformation. ${ }^{28,32,33}$ After drawing (and annealing), lamella retain similar thickness compared to the parent unoriented film, since there is no significant variation in $\mathrm{T}_{\mathrm{m}}$ for the various samples.

When films drawn at $50{ }^{\circ} \mathrm{C}$ are annealed at $110{ }^{\circ} \mathrm{C}$, the extent of the elliptical streak gradually reduced with annealing time (Figure S2 panel f), reflecting a slower change compared to films annealed at $140{ }^{\circ} \mathrm{C}$. A four-point pattern appears initially after annealing and transforms to a two-bar pattern gradually with annealing time. The former suggests a tilted lamellar or herringbone-type arrangement. ${ }^{27,32}$ On further annealing the lamellar orientation evolves until their long axes become perpendicular to the drawing direction. This is depicted in the schematic in Figure 5. Similar to the films annealed at $140^{\circ} \mathrm{C}$, a broad scattering peak appears in the $1 \mathrm{D}$ profiles after annealing at $110{ }^{\circ} \mathrm{C}$ (Figure S4 a), indicating an increase in scattering contrast between lamellae and amorphous regions after annealing. 


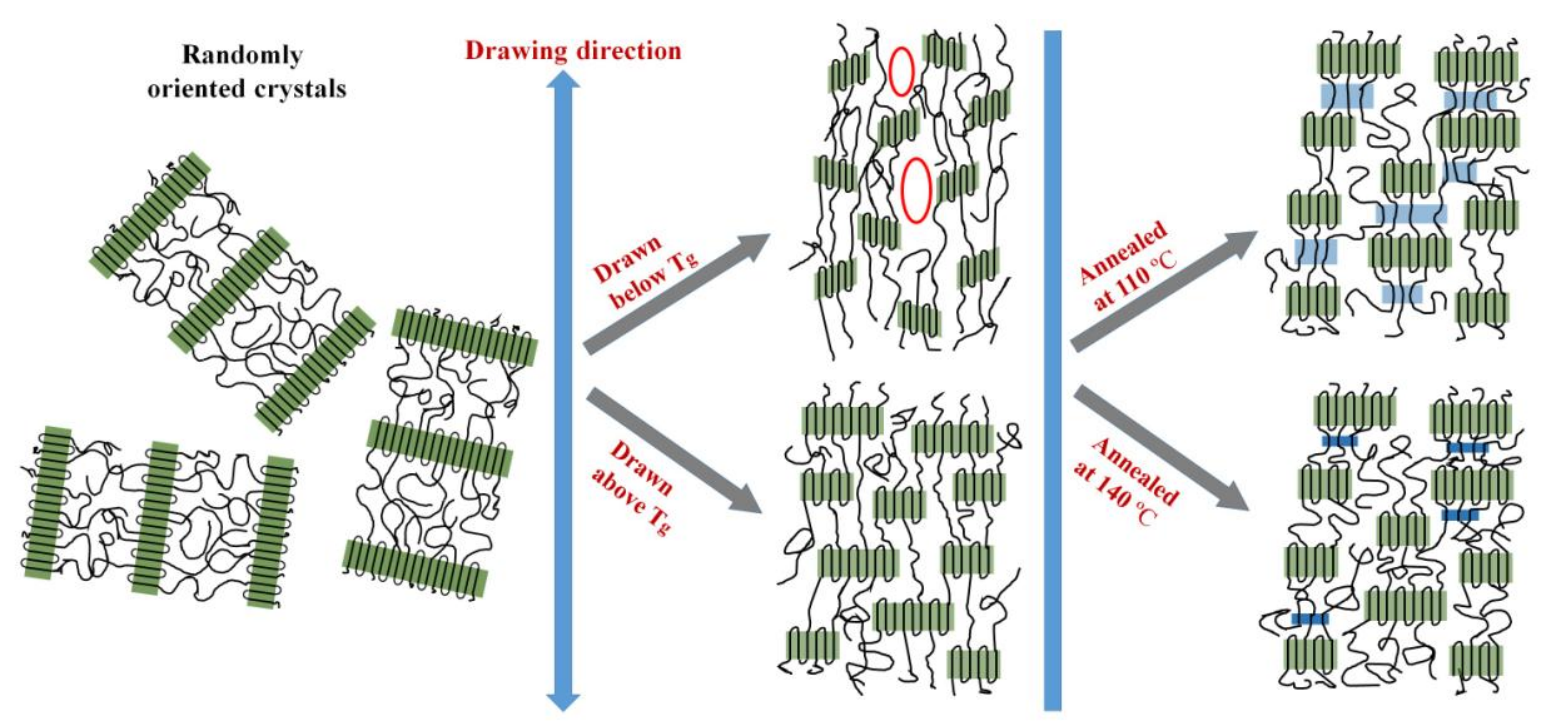

Figure 5. Schematic of morphological changes for films after drawing (middle panel) and annealing (right panel) at different temperatures. Regions highlighted in blue represent dynamically rigid amorphous segments and the red circles represent microvoids.

For the $140 \mathrm{C}-4 \lambda$ film, bar-like features are exhibited in the 2D SAXS pattern (Figure 2b) and the lamellar chain axes are oriented along the drawing direction. The long period is significantly reduced compared to that of the unoriented film, again indicative of lamellar fragmentation/slip on drawing. When annealed at $140{ }^{\circ} \mathrm{C}$, the intensity of the scattering peak increases (Figure 4b), suggesting relaxation of oriented amorphous mesophase segments at $140{ }^{\circ} \mathrm{C}$. Annealing at $110{ }^{\circ} \mathrm{C}$ leads to a more modest increase in scattering peak intensity (Figure S4 b), consistent with the proposal that only a portion of the mesophase relaxes at $110^{\circ} \mathrm{C}$.

\section{Dynamics: Mechanical and Low Field Dielectric Relaxation}

Oscillatory mechanical measurements

After drawing at either $50^{\circ} \mathrm{C}$ or $140{ }^{\circ} \mathrm{C}$, the longitudinal $\mathrm{E}$ ' increases across the entire temperature range, as seen in Figure S5. This arises from the small increase in crystallinity on drawing as well as lamellar and amorphous segment orientation in the draw direction. E' is independent of annealing at $110{ }^{\circ} \mathrm{C}$ but drawn films annealed at $140{ }^{\circ} \mathrm{C}$ exhibit a relatively small decrease in E' over most or all of the experimental temperature window. For the film drawn at $140{ }^{\circ} \mathrm{C}$ the decrease in $\mathrm{E}^{\prime}$ is relatively small and independent of annealing time, 
while for films drawn at $50{ }^{\circ} \mathrm{C}$ the decrease is somewhat greater (and occurs in only 2 minutes, see Figure S5 a). Consistent with the observation in the previous section, this behavior arises from some disordering of amorphous chain segments at the higher annealing temperature.

Up to four relaxations are observed in mechanical loss data (see Figure 6 and S6), and referred to as $\gamma, \beta, \beta_{2}$ and $\alpha$ in order of increasing temperature (see for example Figure 6a). The $\alpha$-process corresponds to the dynamic glass transition, while the lower temperature relaxations have been assigned to local processes. ${ }^{34,35}$ The $\gamma$ process has been assigned to local relaxation in the glassy state involving torsional motions and the $\beta_{2}$ process to a gradual transition from the low temperature orthorhombic to the higher temperature hexagonal crystal form $^{34}$ (and may also have a contribution from greater rotational/librational motion which facilitates the transition ${ }^{36}$ ). The broad $\beta$-process has been proposed to arise from crystalline structural changes, but details remain unclear. ${ }^{35}$

The local processes are not affected by drawing to $4 \lambda$ at either temperature but the $\alpha$ relaxation shifts to somewhat higher temperatures, due to some restriction of amorphous chain segment motion arising from orientation. Annealing also does not influence any of
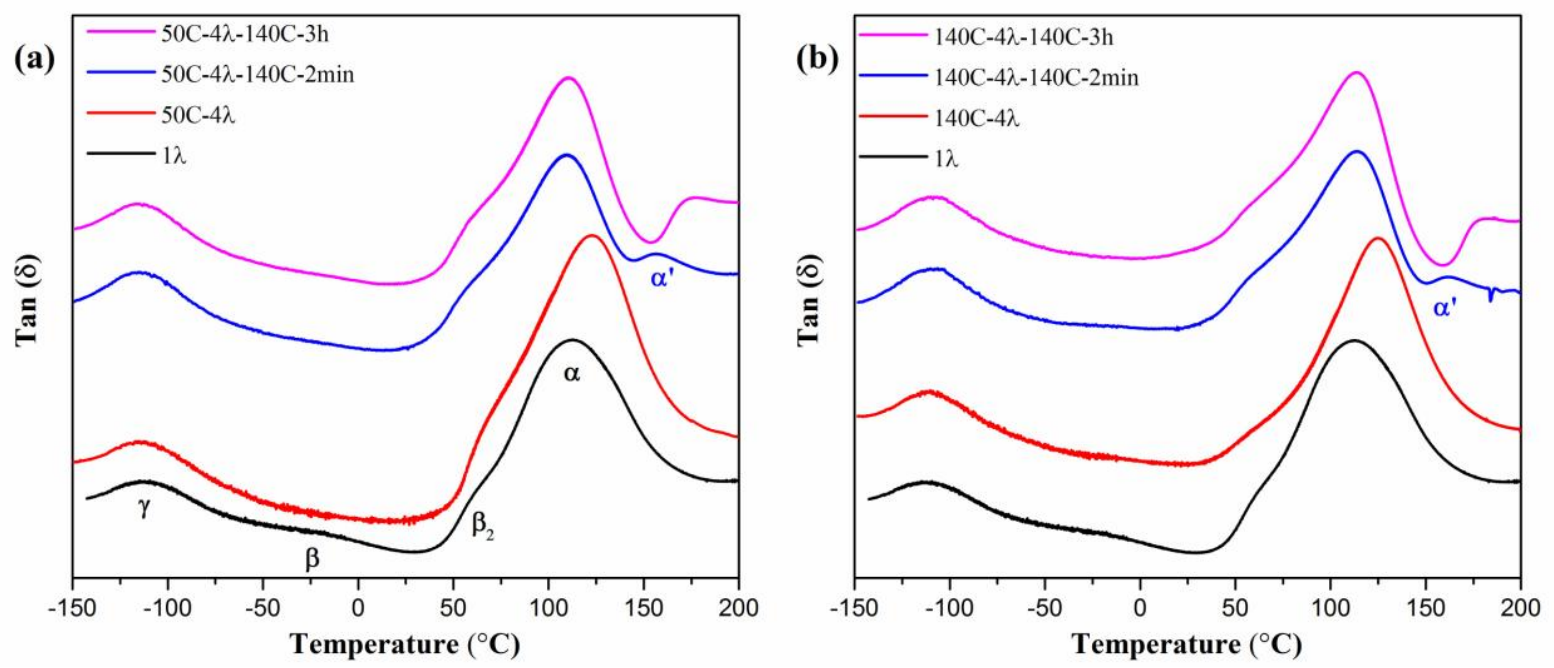

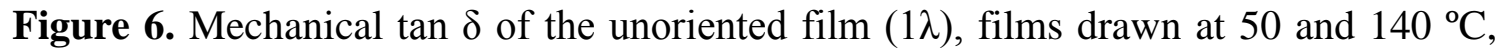
and drawn and annealed at $140{ }^{\circ} \mathrm{C}$.

the local relaxations. However, annealing at $140^{\circ} \mathrm{C}$ for 2 minutes or longer (Figure 6) leads to a decrease in the $\alpha$ process peak temperature to near that of the undeformed film, arising from 
relaxation of the modest constraints on segmental motions associated with this process. In addition, a small relaxation appears at higher temperatures $\left(\alpha^{\prime}\right)$ and shifts to slightly higher temperatures with increasing annealing time. This $\alpha$ ' relaxation appears in the same temperature range and exhibits similar behavior with annealing time as does the DSC 'annealing peak' (see earlier), and seems to arise from relaxation of more dynamically rigid amorphous segments. Annealing at $110^{\circ} \mathrm{C}$ leads to broadly similar changes in the temperature

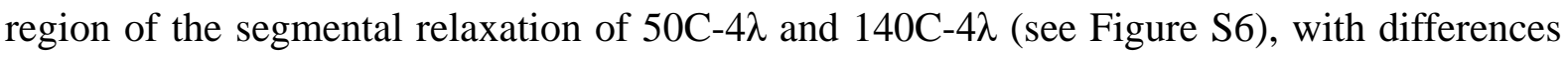
discussed in the supplemental data section.

\section{Dielectric relaxation spectroscopy}

Figure 7 displays representative isochronal dielectric loss spectra vs temperature for two of the materials: $1 \lambda$ and $50 \mathrm{C}-4 \lambda-110 \mathrm{C}-3 \mathrm{~h}$. All mechanical processes are dielectrically active and the dielectric relaxations (at lower frequency) are located in nearly the same temperature location as in the $1 \mathrm{~Hz}$ dynamic mechanical processes: Figure S7 shows isochronal dielectric and mechanical $\tan \delta$ for samples $1 \lambda$ and $50 \mathrm{C}-4 \lambda-110 \mathrm{C}-3 \mathrm{~h}$. Although the relaxation temperatures / times are comparable, the magnitudes of the various relaxations are different, e.g. compare the dielectric relaxation strength ratio of the $\gamma$ and $\alpha$ processes to that of the mechanical relaxations. Dielectric loss spectra also contain a contribution from impurity conduction, prominent in loss spectra at temperatures above the $\alpha$ relaxation and at low frequencies. As noted in our earlier research on ETFE and by others, ${ }^{10,11}$ ETFE possesses quite low dielectric loss at $25^{\circ} \mathrm{C}\left(\tan \delta \sim 10^{-3}\right.$ at $\left.10 \mathrm{~Hz}\right)$ but this increases somewhat at higher frequencies due to contribution from the very broad $\gamma$ relaxation. 

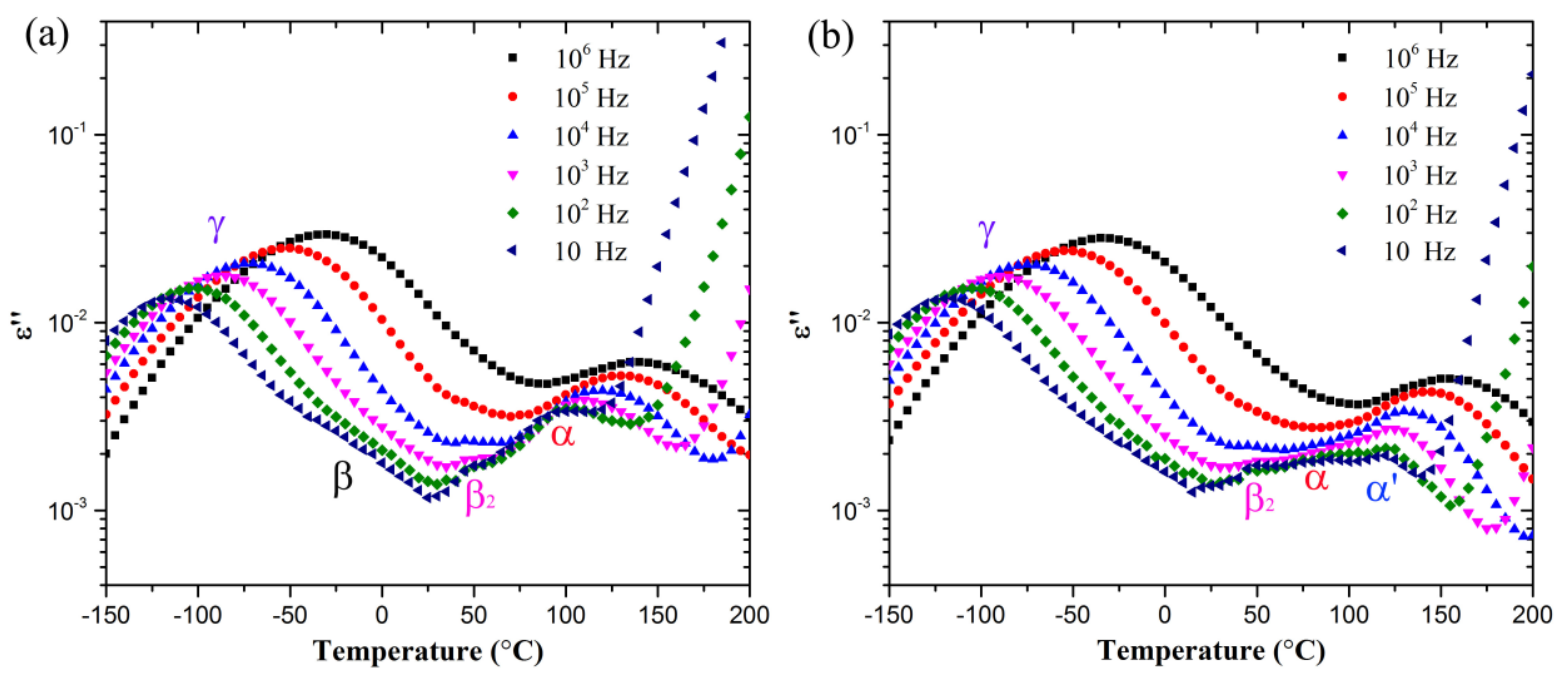

Figure 7. Representative isochronal plots of dielectric loss vs. temperature for (a) $1 \lambda$

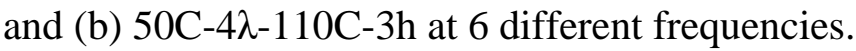

Morphological changes induced by drawing and annealing do not have a significant effect on the overall magnitude of the dielectric loss, but there are changes in the detailed nature of the segmental motions that track with the observations in this region in the mechanical loss (see the previous section). After drawing to $4 \lambda$, the dielectric $\alpha$ process increases in temperature by $\sim 10{ }^{\circ} \mathrm{C}$ compared to that of the unoriented ETFE, then returns to the pre-draw value after annealing at $140{ }^{\circ} \mathrm{C}$. As seen in Figures $7 \mathrm{~b}$ and S7, annealing the $4 \lambda$ drawn film at $110{ }^{\circ} \mathrm{C}$ leads to bifurcation of the $\alpha$ transition region into two processes (see also dynamic mechanical data for drawn films annealed at $110{ }^{\circ} \mathrm{C}$ in Figure $\mathrm{S} 6$ and accompanying discussion). A portion of the amorphous segments relaxes on annealing and exhibits a segmental relaxation whose peak position is lower than that of the unoriented film ( $\alpha$ process). Another population of segments become more dynamically constrained on annealing, exhibiting a higher temperature segmental relaxation ( $\alpha^{\prime}$ process). Close inspection of the $\alpha$ relaxation region in Figure 7b, as well as that in Figure S7, shows that the $\alpha$ relaxation of the drawn and annealed films is associated with the lower temperature side of the broad segmental relaxation of the undeformed ETFE film. 


\section{Dielectric Breakdown}
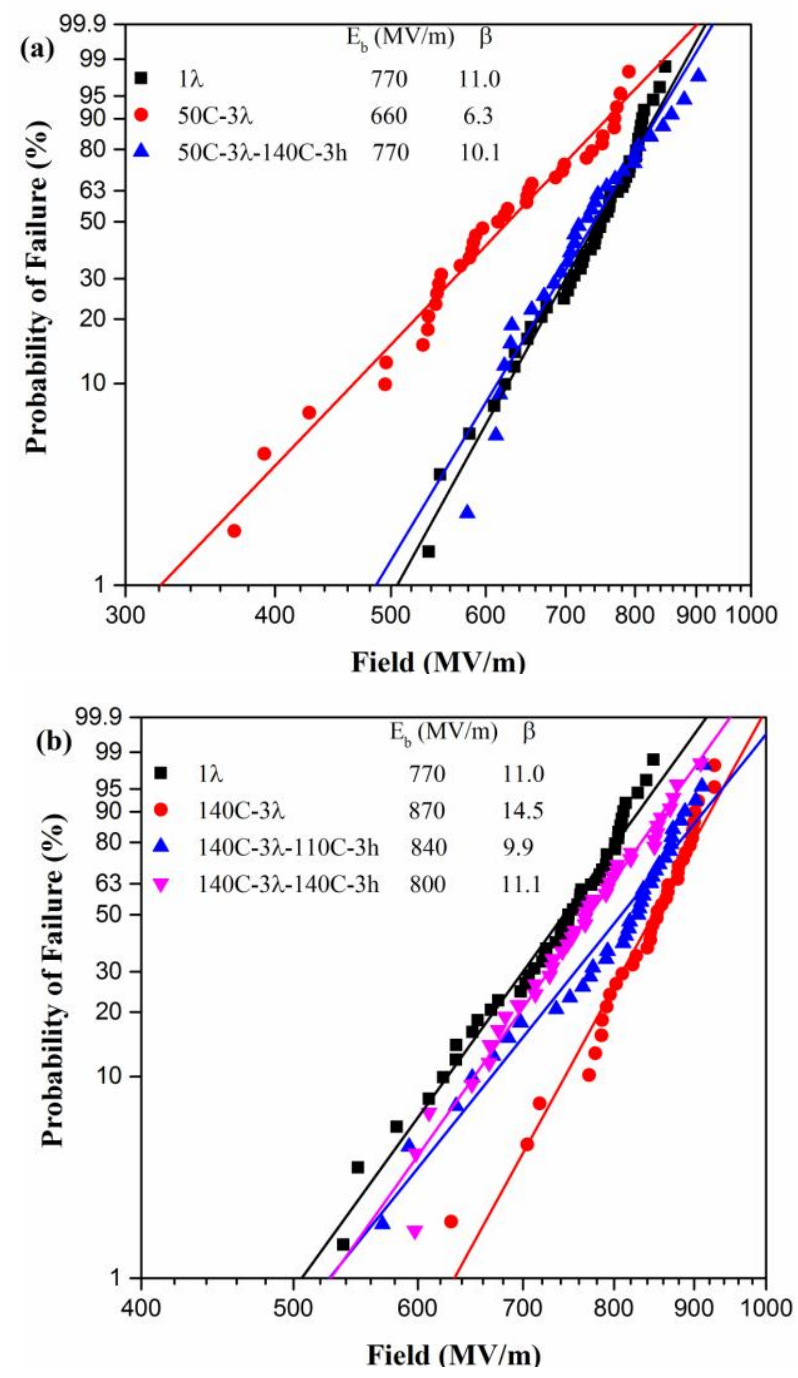

Figure 8. Weibull breakdown field distribution for selected films (a) drawn at $50{ }^{\circ} \mathrm{C}$ and annealed at $140{ }^{\circ} \mathrm{C}$ and (b) drawn at $140{ }^{\circ} \mathrm{C}$ and annealed at different temperatures

Figure 8 shows the Weibull breakdown field distribution of selected ETFE films prepared under different conditions. The characteristic breakdown strength $\left(E_{b}\right)$ of the unoriented film $(1 \lambda)$ is $770 \mathrm{MV} / \mathrm{m}$, which is remarkably high and comparable to $\mathrm{E}_{\mathrm{b}}$ of commercial BOPP measured using comparable methods $\left(760 \mathrm{MV} / \mathrm{m}^{13}\right.$ and $720 \mathrm{MV} / \mathrm{m}^{14}$ ). When drawn at $50{ }^{\circ} \mathrm{C}$ to $3 \lambda(50 \mathrm{C}-3 \lambda)$, the shape parameter $(\beta)$ is lower than that of the undeformed film, indicating a wider probability distribution (Figure 8a). $\mathrm{E}_{\mathrm{b}}$ is also reduced by $\sim 100 \mathrm{MV} / \mathrm{m}$ after drawing at $50{ }^{\circ} \mathrm{C}$ (i.e., below $\mathrm{T}_{\mathrm{g}}$ ). However, after annealing at $140{ }^{\circ} \mathrm{C}$ 


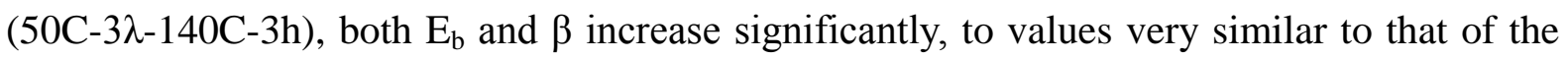
unstretched film. These findings are in keeping with the observation of microvoiding on drawing below $\mathrm{T}_{\mathrm{g}}$ and their elimination after annealing at $140{ }^{\circ} \mathrm{C}$. Gas discharge arising from the presence of voids is well known to negatively impact dielectric breakdown strength of polymers. $^{37}$

The film drawn at $140{ }^{\circ} \mathrm{C}(140 \mathrm{C}-3 \lambda$, Figure $7 \mathrm{~b})$ exhibits a significant increase in $\mathrm{E}_{\mathrm{b}}$ of $\sim 100 \mathrm{MV} / \mathrm{m}$ (to $870 \mathrm{MV} / \mathrm{m}$ ) compared to the parent film, and $\beta$ also increases indicating a narrower probability distribution. These improvements are almost certainly a product of enhanced amorphous segment orientation. The orientation results in a significant increase in storage modulus (Figure S5), an important consideration as electromechanical failure has been identified as a likely mechanism of dielectric breakdown. ${ }^{6,38}$ In addition, the breakdown path can potentially be disrupted by orientation, restricting the propagation routes.

After annealing at $110^{\circ} \mathrm{C}, \mathrm{E}_{\mathrm{b}}$ decreases by a small amount and decreases further (to 800 $\mathrm{MV} / \mathrm{m}$ ) after annealing $140 \mathrm{C}-3 \lambda$ at $140^{\circ} \mathrm{C}$. As discussed earlier, annealing leads to relaxation of oriented amorphous segments, with increasing relaxation at the higher annealing temperature. These findings suggest that the decrease in $\mathrm{E}_{\mathrm{b}}$ on annealing is principally connected to relaxation of oriented amorphous segments, as the degree of crystallinity and lamellar orientation are not significantly affected by the thermal treatments used here. There is a small decrease in modulus (from 4.7 to $3.7 \mathrm{GPa}$ at room temperature) after annealing at these conditions, perhaps slightly diminishing resistance to electromechanical breakdown.

Finally, we recently verified these very promising findings of amorphous orientation and restricted molecular dynamics on a second semi-crystalline fluoropolymer, poly[tetrafluoroethylene-co-(perfluoropropylvinylether)]. ${ }^{39}$ Uniaxial orientation of PFA to $3 \lambda$ at a draw temperature of $140{ }^{\circ} \mathrm{C}$ (above $\mathrm{T}_{\mathrm{g}}$ ) leads to a near doubling of the Weibull breakdown field (to $730 \mathrm{MV} / \mathrm{m}$ ) and achievable stored energy density (to $2.9 \mathrm{~J} / \mathrm{cc}$ ).

\section{Conclusions}

Semi-crystalline ETFE films were drawn at 50 and $140{ }^{\circ} \mathrm{C}$, and annealed at temperatures near and above $\mathrm{Tg}$ (i.e., $110{ }^{\circ} \mathrm{C}$ and $140{ }^{\circ} \mathrm{C}$, respectively). Changes in crystalline microstructure, dynamics and dielectric breakdown were investigated. Drawing to higher 
extension ratio leads to smaller long period, lamellar fragmentation and orientation along the draw direction. A small increase in crystallinity and restricted amorphous segment mobility accompanied drawing. For the film drawn below Tg, lamellar fragments adopt a tilted, herringbone arrangement, and some microvoids are formed on drawing. When drawn at a temperature exceeding Tg, lamellae align along the draw direction without tilting. Annealing has no measureable effect on unit cell orientation and crystallinity, but eliminated any microvoids and leads to relaxation of amorphous segments constrained during drawing. The Weibull breakdown strength decreased after drawing below $\mathrm{Tg}$, then increased to a value similar to that of the undeformed film after subsequent annealing, due to formation and

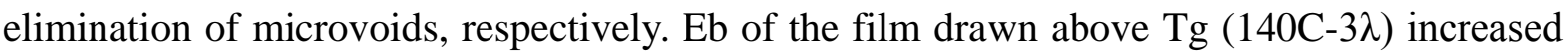
by $\sim 100 \mathrm{MV} / \mathrm{m}$ due to enhanced amorphous segment orientation. Subsequent annealing leads to relaxation of the oriented amorphous segments and a decrease in $\mathrm{E}_{\mathrm{b}}$.

\section{Acknowledgments}

The authors gratefully acknowledge the support of the Office of Naval Research, under grant N00014-14-C-0205.

\section{Appendix A. Supplementary data}

Supplementary data related to this article can be found at XXX.

\section{References}

${ }^{1}$ Nash JL. Biaxially oriented polypropylene film in power capacitors. Polymer Engineering \& Science. 1988;28:862-70.

2 Wang Y, Zhou X, Chen Q, Chu B, Zhang Q. Recent development of high energy density polymers for dielectric capacitors. IEEE Trans. Dielectr. Electr. Insul. 2010;17:1036-42.

${ }^{3}$ Carr JM, MacKey M, Flandin L, Schuele D, Zhu L, Baer E. Effect of biaxial orientation on dielectric and breakdown properties of poly(ethylene terephthalate)/poly(vinylidene fluoride-co-tetrafluoroethylene) multilayer films. J. Polym. Sci. Part B Polym. Phys. 2013;51:882-96.

${ }^{4}$ Li Q, Han K, Gadinski MR, Zhang G, Wang Q, High energy and power density capacitors from solution-processed ternary ferroelectric polymer nanocomposites. Adv. Mater. 2014;26:6244-49. 
${ }^{5}$ Wei J, Zhang Z, Tseng JK, Treufeld I, Liu X, Litt MH, Zhu L. Achieving high dielectric constant and low loss property in a dipolar glass polymer containing strongly dipolar and small-sized sulfone groups. ACS Applied Materials \& Interfaces. 2015;7:5248-55.

${ }^{6}$ Zhou X, Zhao X, Suo Z, Zou C, Runt J, Liu S, et al. Electrical breakdown and ultrahigh electrical energy density in poly (vinylidene fluoride-hexafluoropropylene) copolymer. Applied Physics Letters. 2009;94:162901.

7 Ieda M. Dielectric breakdown process of polymers. Electrical Insulation, IEEE Transactions on. 1980:206-24.

8 Takahashi T, Ohtsuka H, Takehana H, Niwa T. Study on improvements to the dielectric breakdown strength of extruded dielectric cables. Power Apparatus and Systems, IEEE Transactions on. 1985:1945-50.

${ }^{9}$ Ieda M, Nagao M, Hikita M. High-field conduction and breakdown in insulating polymers. Present situation and future prospects. Dielectrics and Electrical Insulation, IEEE Transactions on. 1994;1:934-45.

${ }^{10} \mathrm{Li} \mathrm{L}$, Bowler N, Kessler M, Yoon S. Dielectric response of PTFE and ETFE wiring insulation to thermal exposure. Dielectrics and Electrical Insulation, IEEE Transactions on. 2010;17:1234-41.

11 Miranda DF, Yin C, Zhang S, Runt J. Fluoropolymer microstructure and dynamics: Influence of molecular orientation induced by uniaxial drawing. Polymer. 2016;91:211-21.

12 Yin C, Miranda DF, Zhang SH, Zhang Q, Runt J. Microstructure evolution of poly[tetrafluoroethylene-co-(perfluoropropylvinylether)] films under uniaxial deformation. Polymer. 2016;99:480-87.

13 Zhang S, Zou C, Kushner DI, Zhou X, Orchard Jr RJ, Zhang N, et al. Semicrystalline polymers with high dielectric constant, melting temperature, and charge-discharge efficiency. Dielectrics and Electrical Insulation, IEEE Transactions on. 2012;19:1158-66.

${ }^{14} \mathrm{Xu} \mathrm{CC}$, Ho J, Boggs SA. Automatic breakdown voltage measurement of polymer films. Electrical Insulation Magazine, IEEE. 2008;24:30-4.

15 Ono Y, Kakiage M, Yamanobe T, Yukawa Y, Higuchi Y, Kamiya H, et al. Structural and property changes during uniaxial drawing of ethylene-tetrafluoroethylene copolymer films as analyzed by in-situ X-ray measurements. Polymer. 2011;52:1172-9.

16 Arai K, Funaki A, Phongtamrug S, Tashiro K. Influence of alternating sequential fraction on the melting and glass transition temperatures of ethylene-tetrafluoroethylene copolymer. Polymer. 2010;51:4831-5.

17 Gürsel SA, Schneider J, Ben Youcef H, Wokaun A, Scherer GG. Thermal properties of proton-conducting radiation-grafted membranes. Journal of Applied Polymer Science. 2008;108:3577-85.

18 Russell T, Lin J, Spooner S, Wignall G. Intercalibration of small-angle X-ray and neutron 
scattering data. Journal of Applied Crystallography. 1988;21:629-38.

19 Dissado L. Theoretical basis for the statistics of dielectric breakdown. Journal of Physics D: Applied Physics. 1990;23:1582.

${ }^{20}$ Laihonen SJ, Gustafsson A, Gäfvert U, Schütte T, Gedde U. Area dependence of breakdown strength of polymer films: automatic measurement method. Dielectrics and Electrical Insulation, IEEE Transactions on. 2007;14:263-74.

${ }^{21}$ Laihonen SJ, Gäfvert U, Schütte T, Gedde UW. DC breakdown strength of polypropylene films: area dependence and statistical behavior. Dielectrics and Electrical insulation, IEEE Transactions on. 2007; 14:275-86.

${ }^{22}$ Yeh J, Runt J. Multiple melting in annealed poly (butylene terephthalate). Journal of Polymer Science Part B: Polymer Physics. 1989;27:1543-50.

${ }^{23}$ Saffar A, Ajji A, Carreau PJ, Kamal MR. The impact of new crystalline lamellae formation during annealing on the properties of polypropylene based films and membranes. Polymer. 2014;55:3156-67.

${ }^{24} \mathrm{Xu} \mathrm{H}$, Cebe P. Heat capacity study of isotactic polystyrene: dual reversible crystal melting and relaxation of rigid amorphous fraction. Macromolecules. 2004;37:2797-806.

${ }^{25}$ Wei Z, Song P, Zhou C, Chen G, Chang Y, Li J, et al. Insight into the annealing peak and microstructural changes of poly (L-lactic acid) by annealing at elevated temperatures. Polymer. 2013;54:3377-84.

${ }^{26}$ Pieper T, Heise B, Wilke W. Wide-angle X-ray studies on ethylene-tetrafluoroethylene (ETFE) copolymers. Polymer. 1989;30:1768-75.

${ }^{27}$ Phongtamrug S, Tashiro K, Funaki A, Arai K, Aida S. Structural study of a series of ethylene-tetrafluoroethylene copolymers with various ethylene contents, Part 1: Structure at room temperature investigated for uniaxially-oriented samples by an organized combination of 2D-WAXD/SAXS and IR/Raman spectra. Polymer. 2008;49:561-9.

28 Jiang Z, Tang Y, Men Y, Enderle H-F, Lilge D, Roth SV, et al. Structural evolution of tensile-deformed high-density polyethylene during annealing: scanning synchrotron small-angle X-ray scattering study. Macromolecules. 2007;40:7263-9.

${ }^{29}$ Zuo F, Burger C, Chen X, Mao Y, Hsiao BS, Chen H, et al. An in situ X-ray structural study of olefin block and random copolymers under uniaxial deformation. Macromolecules. 2010;43:1922-9.

${ }^{30}$ Kwon Y, Boller A, Pyda M, Wunderlich B. Melting and heat capacity of gel-spun, ultra-high molar mass polyethylene fibers. Polymer. 2000;41:6237-49.

${ }^{1}$ Ma Q, Pyda M, Mao B, Cebe P. Relationship between the rigid amorphous phase and mesophase in electrospun fibers. Polymer. 2013;54:2544-54.

${ }^{32}$ Liu L-Z, Hsiao BS, Fu BX, Ran S, Toki S, Chu B, et al. Structure changes during uniaxial deformation of ethylene-based semicrystalline ethylene-propylene copolymer. 1. SAXS study. Macromolecules. 2003;36:1920-9. 
33 Jiang Z, Tang Y, Rieger J, Enderle H-F, Lilge D, Roth SV, et al. Structural evolution of tensile deformed high-density polyethylene at elevated temperatures: Scanning synchrotron small-and wide-angle X-ray scattering studies. Polymer. 2009;50:4101-11.

34 Tanigami T, Yamaura K, Matsuzawa S, Ishikawa M, Mizoguchi K, Miyasaka K. Structural studies on ethylene-tetrafluoroethylene copolymer: 2. Transition from crystal phase to mesophase. Polymer. 1986;27:1521-8.

35 Arai K, Funaki A, Aida S, Phongtamrug S, Tashiro K. Influence of the monomer sequential distribution on the mechanical properties and temperature dependence of an ethylene-tetrafluoroethylene copolymer in association with the phase-transition behavior. Journal of Applied Polymer Science. 2009;114:1710-6.

36 Phongtamrug S, Tashiro K, Funaki A, Arai K. Structural study of a series of ethylene-tetrafluoroethylene copolymers with various ethylene contents, Part 2: Phase transition behavior investigated by temperature dependent measurements of X-ray fiber diagrams. Polymer. 2008;49:5072-83.

37 Blythe T, Bloor D. Electrical properties of polymers. 2nd Ed, Cambridge University Press, 2005.

${ }^{38}$ Ieda M, Nagao M, Hikita M. High-field conduction and breakdown in insulating polymers. Present situation and future prospects. Dielectrics and Electrical Insulation, IEEE Transactions on. 1994;1:934-45.

39 Huang Y, Iacob C, Miranda DF, Zhang SH, Runt J. Manuscript in preparation. 


\section{Graphical Abstract:}
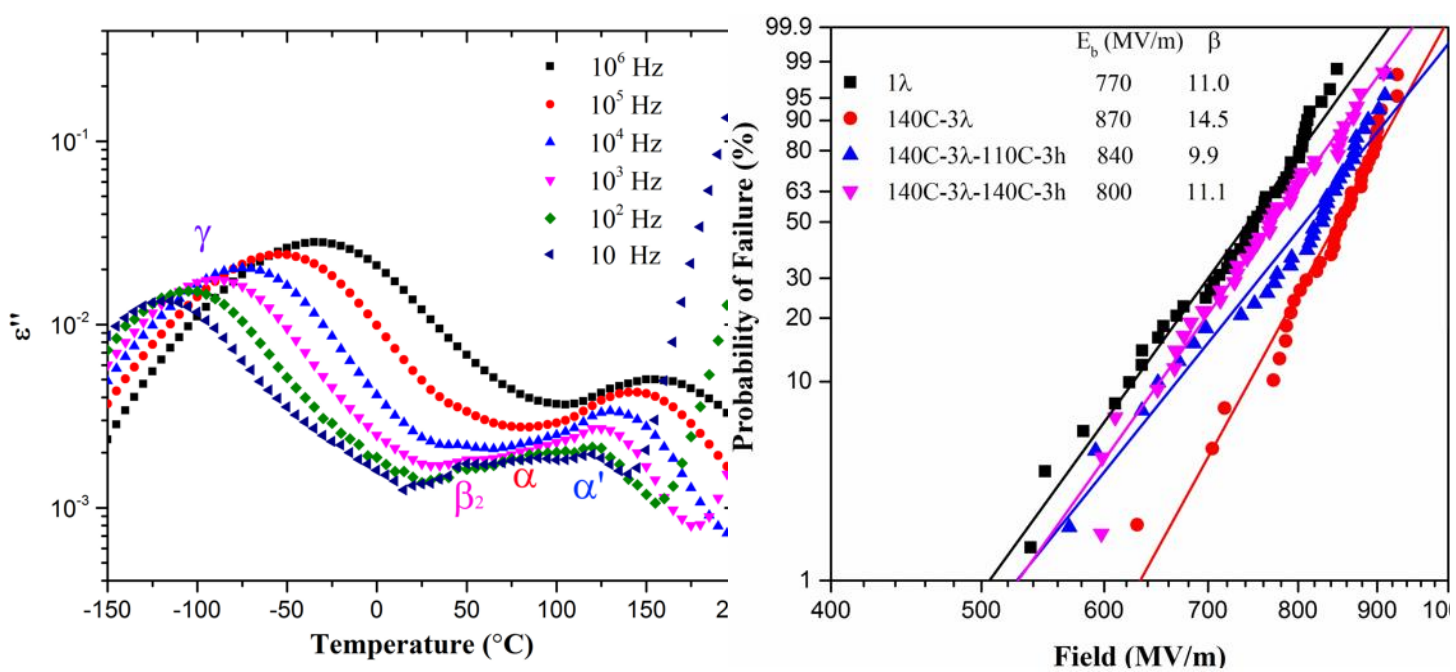